\title{
Torque Quality Improvement of an Open-End Winding PMSM
}

\author{
Nick Hunter \\ Department of Electrical and Electronic Engineering \\ The University Of Nottingham \\ Nottingham, UK \\ nick.hunter@nottingham.ac.uk
}

\author{
Tom Cox \\ Department of Electrical and Electronic Engineering \\ The University Of Nottingham \\ Nottingham, UK \\ thomas.cox@nottingham.ac.uk
}

\author{
Shafiq Ahmed Odhano \\ Department of Electrical and \\ Electronic Engineering \\ The University Of Nottingham \\ Nottingham, UK \\ shafiq.odhano@nottingham.ac.uk
}

\author{
Luca Rovere \\ Department of Electrical and \\ Electronic Engineering \\ The University Of Nottingham \\ Nottingham, UK \\ luca.rovere@nottingham.ac.uk
}

\begin{abstract}
This paper proposes a new closed-loop control strategy which improves the quality of the torque output of an open-end winding (OEW) permanent magnet synchronous motor (PMSM) with common DC bus. Such a configuration provides a path for the zero sequence currents (ZSC) to flow in the windings. The analysis of the system revealed that these currents result in electromagnetic torque oscillation. It has also been established that the zero sequence currents are caused mainly by the third harmonic component of the back electromotive force (EMF). The research and a thorough analysis of the OEW PMSM showed that the existing methods of minimising the torque ripple cannot be applied when the leakage inductance of a machine is small, because the zero sequence component can no longer be considered as one additional degree of freedom that can be managed. Therefore, a new control strategy presented in this paper was proposed. The strategy is validated in simulation.
\end{abstract}

Keywords-Open-end winding PMSM, dual inverter, zero sequence current, torque ripple, adaptive resonant plus PI controller.

\section{INTRODUCTION}

Open-End Winding PMSM drive with a common DC bus features a dual inverter topology and a single DC power source. According to the comparison of the inverter arrangements considered in [1] its major advantages are fault tolerance, compact design, and high torque per volume ratio. In addition, such an arrangement is well suited for the implementation of different power device technologies such as IGBT and Silicon Carbide (SiC). Moreover, such an arrangement allows an increase of output power for a given inverter due to utilisation of the full bus voltage. Due to the aforementioned advantages, not only is the OEW PMSM topology a good candidate for aerospace applications, but also it is appropriate for wind power generation and motor drives operating above certain speeds [2].

However, such a topology does have some drawbacks. One issue is that the output electromagnetic torque becomes a function of both the third harmonic back EMF and the ZSC. Moreover, there are two parts of the OEW PMSM drive that happen to be the sources of ZSC: the inverter side and the actual OEW PMSM side. The ZSC caused by the inverter side can be minimised by introducing a special modulation [3] that eliminates the zero sequence voltage (ZSV). In addition, the ZSV caused by dead-time [4] can also be compensated [5] [6]. Hence, in this paper only the torque ripple due to the third harmonic back EMF is considered as the source of the oscillation. [7]
Different torque ripple minimisation techniques were considered previously such as the usage of PI [8] with back EMF Feed Forward Compensation [9] or the use of PR control to minimise the ZSC [10]. However, all of the mentioned methods of minimisation of the torque ripple are based on the suppression or minimisation of the zero sequence current by introducing zero-sequence voltage in the system. It appears that there is no research work that has been focused on the minimisation of the torque ripple using alternative methods, rather than the suppression of ZSC. Moreover, in cases when a machine has a considerably low leakage inductance none of those methods will work because the low leakage inductance dramatically restricts the amount of ZSV that can be applied to the system. Some high speed machines would not tolerate any ZSV in the drive due to their tendency of having a very low leakage inductance. The argument is that the high speed machines have less stator coil turns. Thereby, the inductance happens to be considerably low. Less wire turns also result in a lower leakage inductance. Such an inductance could induce a high ZSC spikes in the stator if ZSV is introduces even for a short period of time. However, when the ZSV is not applied, the ZSC becomes induced from another source, such as the $3^{\text {rd }}$ harmonic back EMF. This current causes a torque disturbance. A new, alternative control method that improves the torque quality of such an open-end winding drive configuration has been proposed. The developed method uses a proportional integral plus adaptive resonant controller $(\mathrm{PI}+\mathrm{RC})$ on the quadrature current branch in order to compensate the torque ripple caused by the ZSC due to the $3^{\text {rd }}$ harmonic of the back EMF.

\section{MODELING OF THE OEW PMSM OUTPUT TORQUE}

The diagram of an OEW PMSM drive with common DC link is presented in Fig. 1.

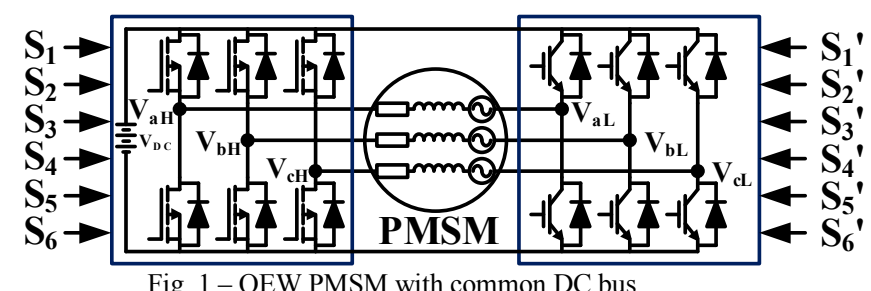

Fig. 1 - OEW PMSM with common DC bus

The stator voltage equation, represented in the machine variables:

$$
V_{a b c}=r_{s} i_{a b c}+p \lambda_{a b c}
$$


where, $r_{s}$ - stator winding resistance diagonal matrix, $i_{a b c}-$ stator phase currents vector, $\lambda_{a b c}-$ stator phase flux linkage vector and $p$ is a derivative with respect to time $\left(\frac{d}{d t}\right)$ operator. The core losses are neglected for simplicity.

The matrix components, in turn, are represented in the set of equations (2).

$$
\begin{gathered}
r_{s}=\left[\begin{array}{ccc}
r_{s} & 0 & 0 \\
0 & r_{s} & 0 \\
0 & 0 & r_{s}
\end{array}\right] ; V_{a b c}=\left[\begin{array}{c}
V_{a} \\
V_{b} \\
V_{c}
\end{array}\right] \\
i_{a b c}=\left[\begin{array}{c}
i_{a} \\
i_{b} \\
i_{c}
\end{array}\right] ; \lambda_{a b c}=\left[\begin{array}{c}
\lambda_{a} \\
\lambda_{b} \\
\lambda_{c}
\end{array}\right] ;
\end{gathered}
$$

The stator phase flux linkage $\lambda_{a b c}$, in turn, is related to the stator currents $i_{a b c}$ and the rotor fundamental $\lambda_{a b c(r 1)}$ and the third harmonic $\lambda_{a b c(r 3)}$ permanent magnet flux through the following equation:

$$
\lambda_{a b c}=L_{s} i_{a b c}+\lambda_{a b c(r 1)}+\lambda_{a b c(r 3)}
$$

The inductance matrix $L_{s}$, in turn, is a $3 \times 3$ matrix [11]:

$$
\begin{gathered}
L_{s}=\left[\begin{array}{lll}
L_{a a} & L_{a b} & L_{a c} \\
L_{b a} & L_{b b} & L_{b c} \\
L_{c a} & L_{c b} & L_{c c}
\end{array}\right] \\
\lambda_{a b c(r 1)}=\lambda_{p m}\left[\begin{array}{c}
\sin \left(\theta_{e}\right) \\
\sin \left(\theta_{e}-\frac{2}{3} \pi\right) \\
\sin \left(\theta_{e}+\frac{2}{3} \pi\right)
\end{array}\right] \\
\lambda_{a b c(r 3)}=\lambda_{p m} K_{p m 3}\left[\begin{array}{c}
\sin \left(3 \theta_{e}\right) \\
\sin \left(3\left(\theta_{e}-\frac{2}{3} \pi\right)\right) \\
\sin \left(3\left(\theta_{e}+\frac{2}{3} \pi\right)\right)
\end{array}\right]
\end{gathered}
$$

where, $L_{a a}, L_{b b}$ and $L_{c c}$ are the self-inductances of the phases $\mathrm{A}, \mathrm{B}$ and $\mathrm{C}$, respectively, and the off-diagonal terms are the mutual inductances between the phases, $\lambda_{p m}$ is the amplitude of flux linkage established by the permanent magnet and $K_{p m 3}$ is one third of the ratio of the amplitude of the open circuit $3^{\text {rd }}$ harmonic back EMF and fundamental back EMF, respectively, induced in either of the stator windings. $\theta_{e}$ is the electrical angle value of the rotor.

However, converting (1) to rotor reference frame, a set of the PMSM voltage equations can be written as:

$$
\left\{\begin{array}{c}
V_{q}=r_{s} i_{q}+L_{q} \frac{d i_{q}}{d t}+\omega_{e} L_{d} i_{d}+\omega_{e} \lambda_{p m} \\
V_{d}=r_{s} i_{d}+L_{d} \frac{d i_{d}}{d t}-\omega_{e} L_{q} i_{q} \\
V_{0}=r_{s} i_{0}+L_{0} \frac{d i_{0}}{d t}+3 \omega_{e} \lambda_{p m} K_{p m 3} \cos \left(3 \theta_{e}\right)
\end{array}\right.
$$

where, the parameters with the subscripts $q, d, 0$ are the quadrature, the direct and the zero sequence parameters, respectively, $\omega_{e}$ is the rotor electrical speed.

Instantaneous power $P_{e}$ flowing in the machine can be written in both the machine variables and the rotor reference frame, respectively, as shown in (6).

$$
\begin{aligned}
P_{e}=V_{a} i_{a}+V_{b} i_{b} & +V_{c} i_{c} \\
& =\frac{3}{2}\left(V_{q} i_{q}+V_{d} i_{d}+2 V_{0} i_{0}\right)
\end{aligned}
$$

Substituting (5) into (6) for the steady state and excluding stator copper losses, the electromagnetic power $P_{e m}$ utilised for the conversion of energy from electrical to mechanical is drawn in (7).

$$
\begin{aligned}
P_{e m}=\left(\frac{3}{2}\right) \omega_{e}\left[i_{q} \lambda_{p m}+i_{q} i_{d}\left(L_{d}-L_{q}\right)\right. \\
\left.+6 i_{0} \lambda_{p m} K_{p m 3} \cos \left(3 \theta_{e}\right)\right]
\end{aligned}
$$

Besides, the power- torque relation can be written as:

$$
P_{e m}=T_{e}\left(\frac{2}{P}\right) \omega_{e}
$$

where, $T_{e}$ is the electromagnetic torque, $P$ is the number of machine's poles and $\omega_{e}$ is the electrical frequency. Substituting (8) into (7), the torque produced by the machine appears to be written as:

$$
\begin{aligned}
T_{e}=\left(\frac{3}{2}\right)\left(\frac{P}{2}\right)\left[i_{q} \lambda_{p m}+i_{q} i_{d}\left(L_{d}-L_{q}\right)\right. \\
\left.+6 i_{0} \lambda_{p m} K_{p m 3} \cos \left(3 \theta_{e}\right)\right]
\end{aligned}
$$

The ZSC, in turn, is sinusoidal in nature with a frequency of a third harmonic the amplitude of which was derived from (5) as a function of the motor speed $\omega_{e}$ as shown in (10).

$$
\left|i_{0}\right|_{\left(V_{0}=0\right)}=\frac{-3 \omega_{e} \lambda_{p m} K_{p m 3}}{\sqrt{r_{s}^{2}+9 \omega_{e}^{2} L_{0}^{2}}}
$$

Hence, the amplitude of the torque oscillations depends mainly on the speed of the motor rather than on the amount of the produced average torque. Therefore, this zero sequence current induces the torque oscillation regardless of the value of the average torque.

\section{Proposed CONTROL Method}

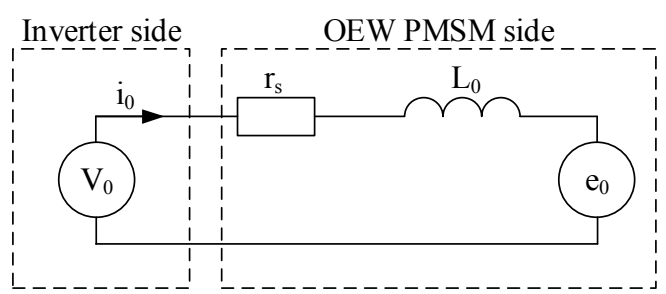

Fig. 2 - Equivalent circuit of zero sequence component of OEW PMSM

The equivalent circuit of the zero sequence component is shown in Fig. 2. In case of a high DC bus voltage and a low leakage inductance $\left(\mathrm{L}_{0}\right)$ an introduction of a pulse of $\mathrm{ZSV}\left(\mathrm{V}_{0}\right)$ may result in unacceptable spikes of ZSC $\left(\mathrm{i}_{0}\right)$. Hence, the suppression of the ZSC by the means of the inverter's ZSV is not an option. It only remains to mitigate the influence of the ZSC due to the third harmonic back EMF $\left(\mathrm{e}_{0}\right)$ on the output torque quality. Thus, a new control technique was proposed in order to eliminate the variation of the torque due to the zero sequence component without introducing $\mathrm{V}_{0}$. According to (9) the electromagnetic torque produced by the machine has an oscillation due to the cosine term which, in turn, is a result of both the back EMF $3^{\text {rd }}$ harmonic and a zero sequence current produced by the same harmonic. Hence, if this term is compensated by one of the remaining terms the resultant torque must be free from this oscillation. Assuming $i_{d}$ is zero, hence, the equation (9) becomes: 


$$
\begin{aligned}
& T_{e}=\left(\frac{3}{2}\right)\left(\frac{P}{2}\right)\left[i_{q} \lambda_{p m}\right. \\
& \left.+6 i_{0} \lambda_{p m} K_{p m 3} \cos \left(3 \theta_{e}\right)\right]
\end{aligned}
$$

Forcing $i_{q}$ to be as shown in equation (12):

$$
i_{q}^{*}=i_{q D C}{ }^{*}-i_{q A C}{ }^{*}
$$

where, $i_{q D C}{ }^{*}$ and $i_{q A C}{ }^{*}$ are the constant and the alternating terms of the reference quadrature current $i_{q}{ }^{*}$, respectively. The value $i_{q D C}{ }^{*}$ is the main source of the average torque generation, whereas $i_{q A C}{ }^{*}$ is the torque oscillation compensating term, denoted in (13).

$$
i_{q A C}{ }^{*}=6 i_{0} K_{p m 3} \cos \left(3 \theta_{e}\right)
$$

Combining (13) and (12), subsequently substituting the result into (11), the electromagnetic torque equation becomes the one show in (14).

$$
\begin{aligned}
T_{e}=\left(\frac{3}{2}\right)\left(\frac{P}{2}\right)[ & \left(i_{q D C}{ }^{*}\right) \lambda_{p m} \\
& -6 i_{0} \lambda_{p m} K_{p m 3} \cos \left(3 \theta_{e}\right) \\
& \left.+6 i_{0} \lambda_{p m} K_{p m 3} \cos \left(3 \theta_{e}\right)\right]
\end{aligned}
$$

The oscillating terms of (14) cancel out leaving the torque value to be as follows.

$$
T_{e}=\left(\frac{3}{2}\right)\left(\frac{P}{2}\right)\left(i_{q D C}^{*}\right) \lambda_{p m}
$$

According to (15) the oscillation due to the zero sequence current is cancelled, hence, the value of the torque is no longer oscillatory. In order to implement the proposed control technique, a proportional integral plus resonant controller $(\mathrm{PI}+\mathrm{RC})$ is used for the quadrature current loop, the basic simulation diagram of which is shown in Fig. 3.

The process of derivation of $i_{0}$ is rather simple and does not involve the rotor position as per equation (16).

$$
i_{0}=\frac{i_{a}+i_{b}+i_{c}}{3}
$$

According to the zero-sequence voltage equation of (5), the zero sequence current has a form of a sinusoid, (17), if there is precisely zero ZSV applied to the motor.

$$
i_{0}=\left|i_{0}\right| \cos \left(3 \theta_{e}+\gamma\right)
$$

where, $i_{0}$ and $\left|i_{0}\right|$ are the zero-sequence current's instantaneous value and its amplitude, respectively, when the applied zero sequence voltage is zero. $3 \theta_{e}$ and $\gamma$ are the angle and the phase of ZSC, respectively.

Substituting (17) into (13):

$$
i_{q A C}{ }^{*}=6\left|i_{0}\right| K_{p m 3} \cos \left(3 \theta_{e}+\gamma\right) \cos \left(3 \theta_{e}\right)
$$

Using trigonometric identity, the equation (18) becomes:

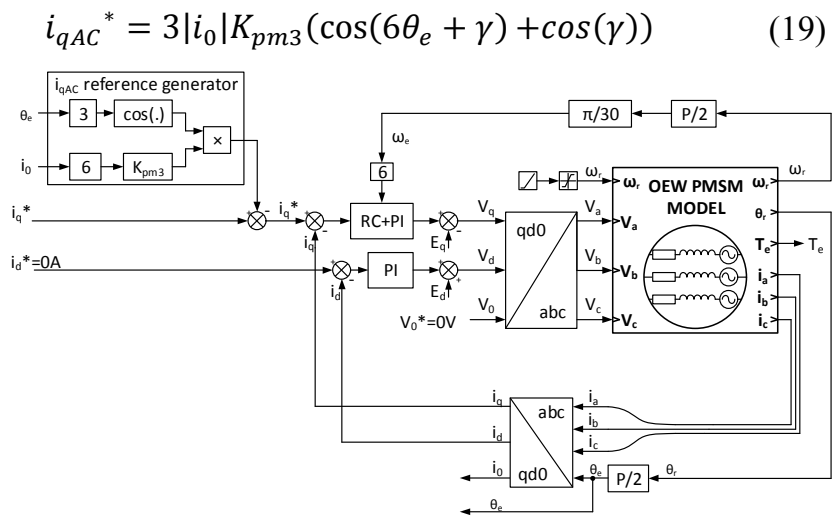

Fig. 3 - Basic Quadrature Current PI+RC simulation setup

According to equation (19) it is clear that the alternating part of the quadrature reference current has a frequency of six times the fundamental frequency.

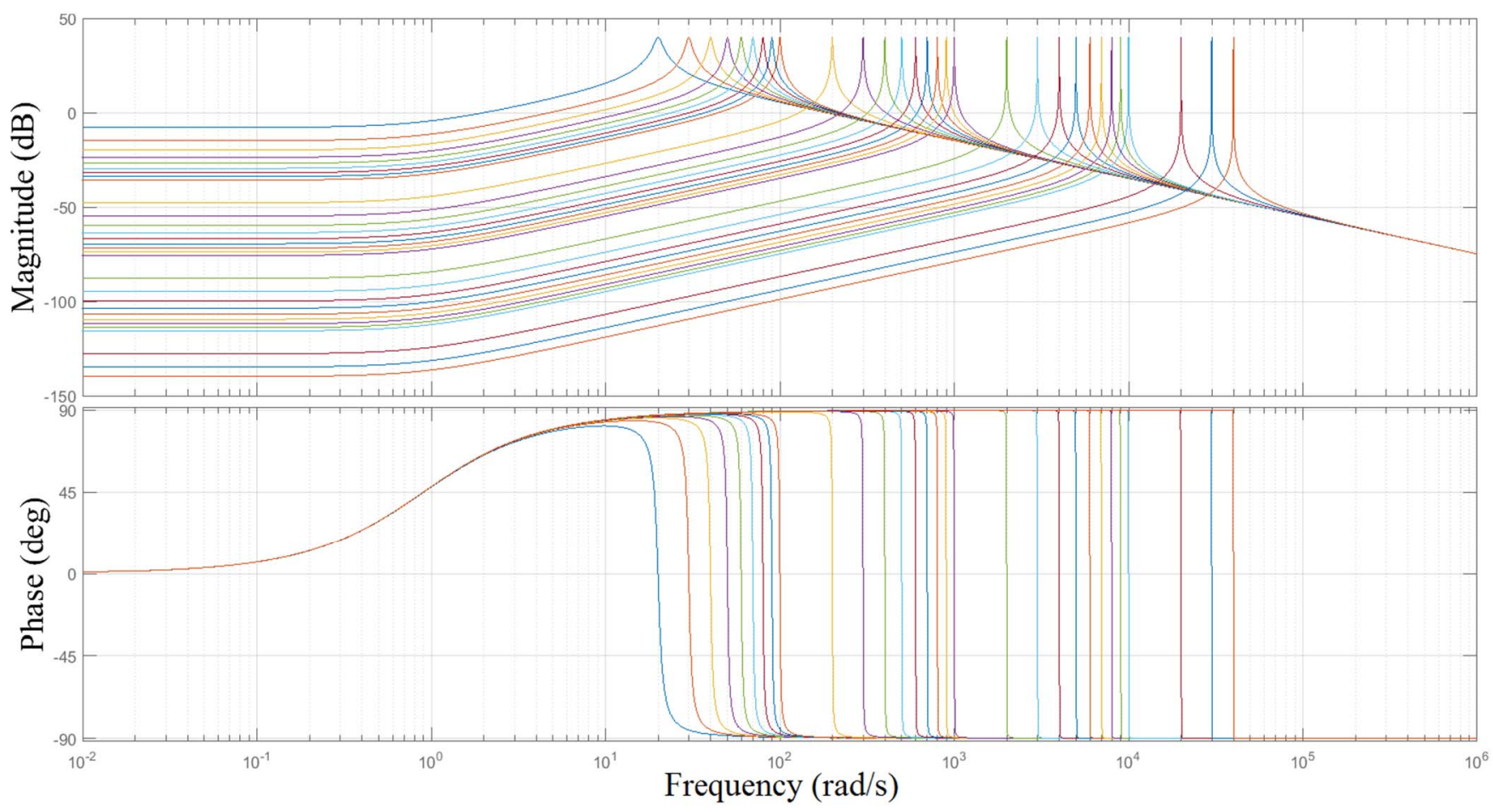

Fig. 4 - Bode diagram of the resonant controller according to the range of the input frequencies 
Hence, the RC, depicted in Fig. 3 is fed with the sixth harmonic electrical frequency $\left(6 \omega_{e}\right)$.

In order to improve the current control the feed-forward $E_{q}$ and $E_{d}$ terms were introduced to compensate the cross coupling, as per Fig. 3.

A special form of a non-ideal adaptable resonant controller proposed in [12] is shown in equation (20). Such a controller is used to maintain the $\mathrm{AC}$ reference of the quadrature current and a conventional PI is used in order to maintain the DC reference of the same current, Fig. 3.

$$
G_{f r c}(s)=\frac{2 k_{i r}\left(\omega_{c r} s+\omega_{c r}{ }^{2}\right)}{s^{2}+2 \omega_{c r} s+\omega_{c r}{ }^{2}+\omega_{0}{ }^{2}}
$$

where, $k_{i r}$ is the gain, $\omega_{0}$ is the resonant frequency and $\omega_{c r}$ is the controller width. All of the derivations for the adaptable resonant controller can be found in [12]. The following parameters were chosen for the RC: $k_{i r}=100, \omega_{c r}=0.9, \omega_{0}$ is the fed back electrical speed of the motor multiplied by six $\left(6 \omega_{e}\right)$ as discussed above. The Bode diagram of such a resonant controller is shown in Fig. 4. The peaks correspond to the particular value of the speed that $\omega_{0}$ input takes.

The DC parts of the reference and feedback input signals of the RC does not affect its behaviour due to the nature of the RC. A properly tuned resonant controller responds to a particular resonant frequency only, considerably attenuating all of the other frequencies and especially DC value, as depicted in Fig. 4. In this case the resonant frequency is directly proportional to the speed of the rotor.

\section{SimULATION RESULtS}

The basic performance of the proposed control concept shown in Fig. 3 was tested in Matlab/Simulink using the parameters listed in TABLE I.

TABLE I 3-PHASE OEW PMSM SPECIFICATION

\begin{tabular}{|c|c|}
\hline Parameter & Value \\
\hline Rated Speed, $\omega_{\text {r rated }}$ & $20 \mathrm{kRPM}$ \\
\hline Phase Resistance, $R_{s}$ & $164 \mathrm{~m} \Omega$ \\
\hline q-axis Inductance, $L_{q}$ & $355 \mu \mathrm{H}$ \\
\hline d-axis Inductance, $L_{d}$ & $355 \mu \mathrm{H}$ \\
\hline Leakage Inductance, $L_{0}$ & $17.75 \mu \mathrm{H}$ \\
\hline PM Flux Linkage, $\lambda_{p m}$ & $71.5 \mathrm{mVs}$ \\
\hline $3^{\text {rd }}$ Harmonic Flux Linkage coefficient, $K_{p m 3}$ & 0.0115 \\
\hline Poles, $P$ & 6 \\
\hline Rated Current, $I_{\max }$ & $150 \mathrm{~A}$ \\
\hline Rated Voltage, $V_{D C}$ & $540 \mathrm{~V}$ \\
\hline
\end{tabular}

The machine's leakage inductance is around $5 \%$, hence, introducing the $540 \mathrm{~V}$ DC bus, even for as little as one microsecond, could result in a spike of the ZSC of approximately $30 \mathrm{~A}$. Such a behaviour is undesirable. Hence, the new control strategy presented in this paper that does not introduce any ZSV on the inverter side is the appropriate solution to minimise the torque ripple output due to the third harmonic of the back EMF in such types of the machines. According to the simulation outcome presented in Fig. 6 (top), the proposed control method resulted in the complete elimination of the torque ripple due to the third harmonic back EMF. The bottom graph shows that in order to achieve such a result the phase current was only slightly impacted.

The quadrature, direct and zero axis currents are respectively shown in Fig. 7. The adaptable resonant controller made sure the oscillatory path is followed correctly in order to achieve smooth torque output. The zero sequence current remained uncontrolled as expected. It can be noticed that it oscillates at the frequency of the third harmonic with an amplitude predicted by equation (10). Even though the zero sequence current is present in the system for the entire time of operation- the ability to increase the power output by using the OEW PMSM configuration outweigh this drawback in some situations. Referring back to equations (9) and (10) along with the torque results in Fig. 6 it is very important to note that the torque ripple amplitude is independent of the average torque value. This amplitude is proportional to the ZSC amplitude which, in turn, is proportional to the speed of the machine. This means that such open-end winding machines will have a considerably large value of the torque ripple percentage particularly at the low average load torque. However, the basic simulation showed that the proposed method eliminated the ripple regardless of the average torque value.

Although, mathematically it might seem as a good method to fully suppress the torque ripple, in reality the input phase voltages are modulated using switching inverters, which, in turn, induce an additional current noise due to the switching. Hence, a more accurate simulation method was introduced taking into account a special space vector voltage modulation technique (SVM) which eliminates the ZSV produced by the voltage source converter (VSC) by using only certain voltage vectors that do not produce ZSV. The particular voltage vectors are depicted in Fig. 8 in red. Thereby, according to Fig. 8, the voltage limit for the VSC appears to be $V_{D C}$ (magenta circle). This technique is explained in [3]

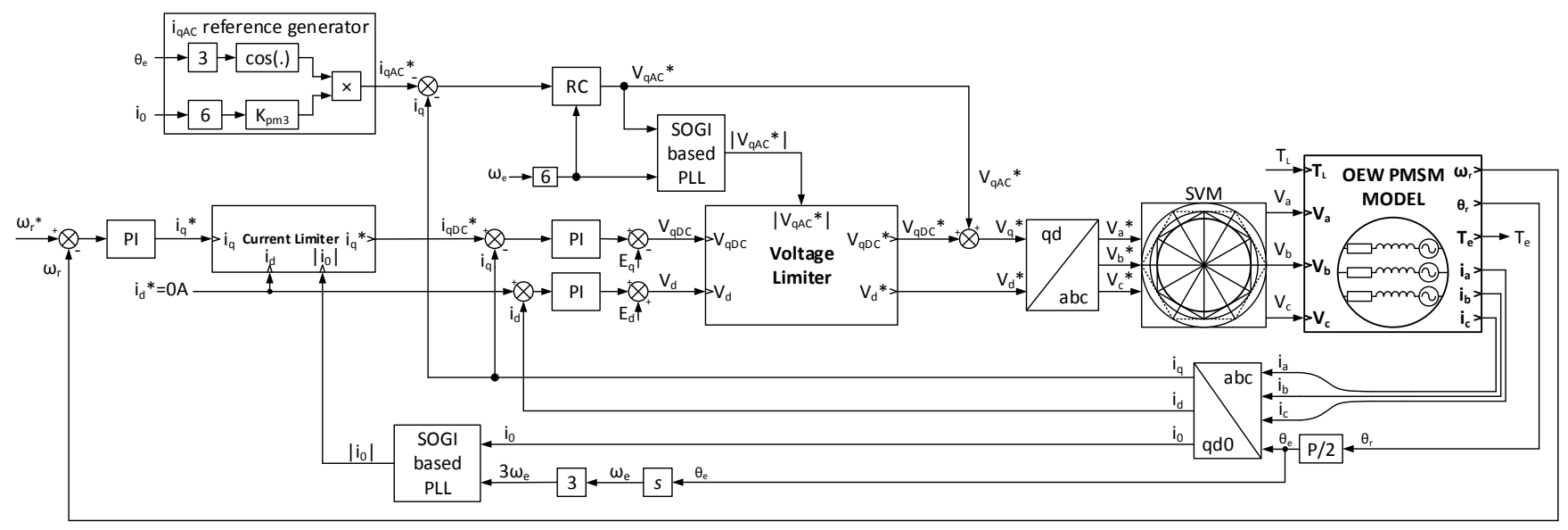

Fig. 5 - The full detailed simulation block diagram featuring voltage modulation 

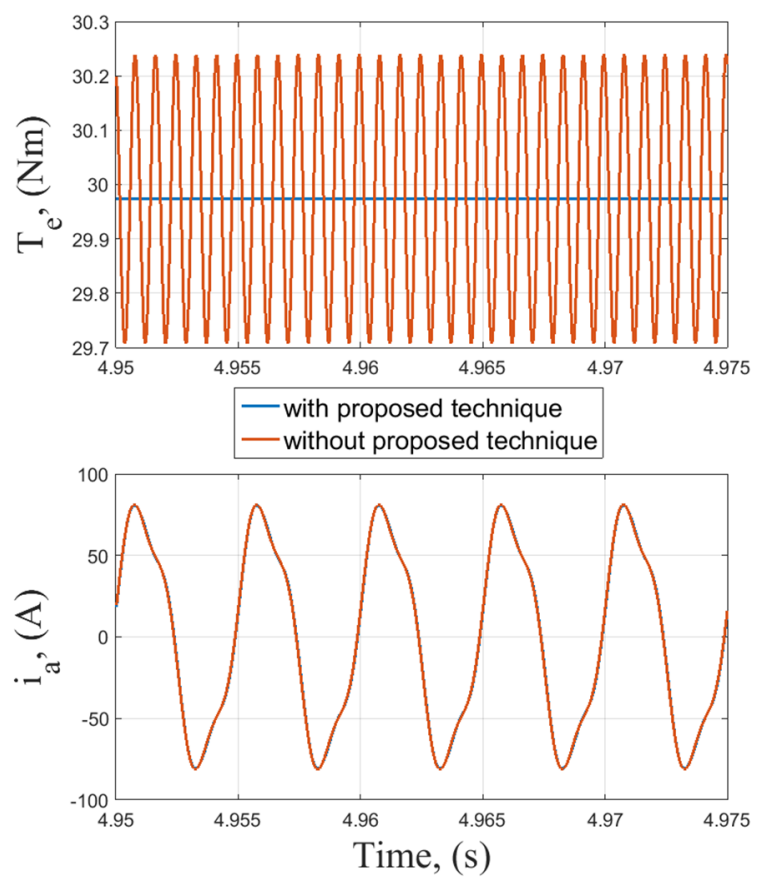

Fig. 6 - Electromagnetic torque (top) and phase current (bottom) at $200 \mathrm{~Hz}$ electrical speed

A new simulation illustrated in Fig. 5 features a special modulation technique that is used in order to keep the ZSV always zero. The simulation clock frequency was set to be the same as the carrier counter of the actual modulator, $100 \mathrm{MHz}$. Hence, the simulation very accurately mimics the behaviour of an FPGA based modulator.

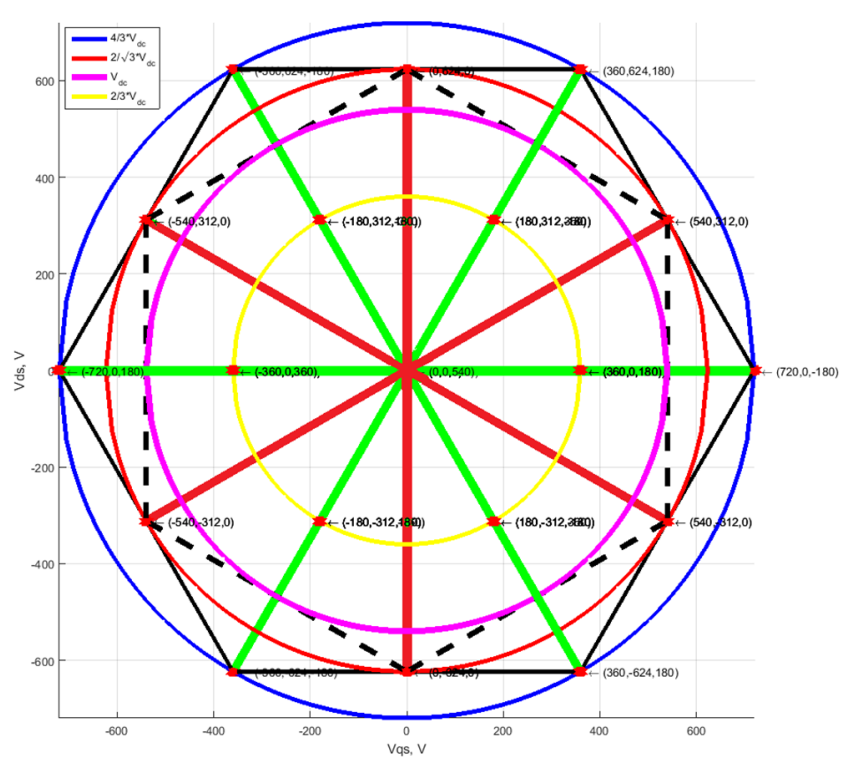

Fig. 8 - SVM diagram for the dual fed inverter

The sampling frequency of the controller was set to be 40 $\mathrm{kHz}$ to represent the actual switching frequency of a $\mathrm{SiC}$ inverter. The electrical rotor frequency was stabilised at 200 Hz. The output of the speed loop PI controller generates the DC reference for $i_{q}$. This current reference is limited by a special current limiter that takes into consideration the direct current and the amplitude of the ZSC in order to provide the machine with the maximum allowed RMS current. The RMS value of a signal is a square root of the squares of all of the harmonics RMS values that comprise the signal itself. The
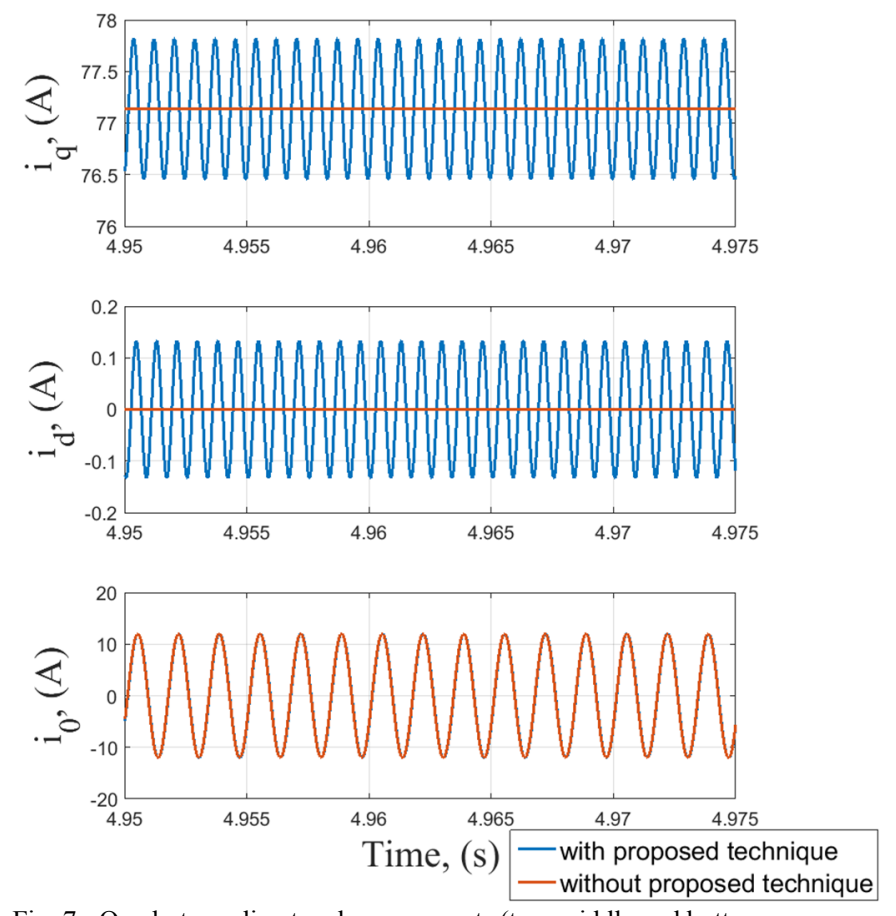

Fig. 7 - Quadrature, direct and zero currents (top, middle and bottom, respectively) at $200 \mathrm{~Hz}$ electrical speed

phase current of the considered OEW PMSM consists of the fundamental and the zero sequence currents mainly. Hence, the following equation appears to be an appropriate limit for the phase current.

$$
I_{R M S_{-} \text {lim }}=\sqrt{\left(\frac{\sqrt{i_{q D C_{-} \text {lim }}{ }^{2}+i_{d}^{2}}}{\sqrt{2}}\right)^{2}+\left(\frac{\left|i_{0}\right|}{\sqrt{2}}\right)^{2}}
$$

where, $I_{R M S_{-} \text {lim }}$ is the RMS current limit, $i_{q D C_{-} \text {lim }}$ is a particular limit for the quadrature current, $i_{d}$ is the direct current, and $\left|i_{0}\right|$ is the amplitude of the zero-sequence current. Solving the equation (21) for $i_{q D C_{-} \text {lim }}$ :

$$
i_{q D C_{-} \text {lim }}=\sqrt{2 I_{R M S_{-} l i m}{ }^{2}-i_{d}{ }^{2}-\left|i_{0}\right|^{2}}
$$

The amplitude of the zero sequence current is provided by the modified version of the second order generalised integrator (SOGI) based single phase Phase-Locked-Loop (PLL) (Fig. 5), explained in [13]. The modification added is the amplitude identification bit at the output of the mentioned PLL, as illustrated in

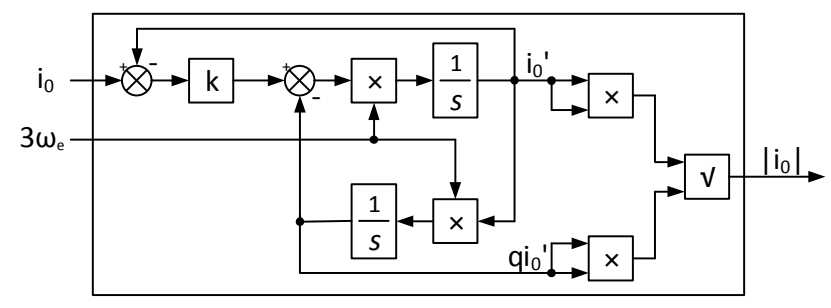

Fig. 9 - SOGI based single phase PLL amplitude estimator

The direct $i_{0}{ }^{\prime}$ and the quadrature $q i_{0}{ }^{\prime}$ output signals are used in the following formula to calculate the ZSC amplitude, $\left|i_{0}\right|$, for the current limiter. 


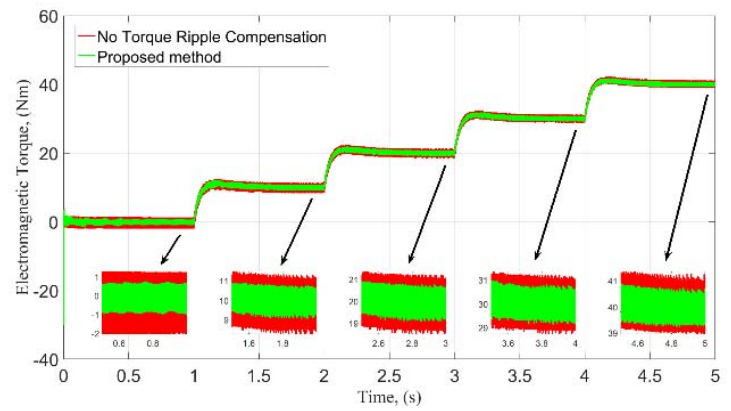

Fig. 10 - Electromagnetic torque comparison

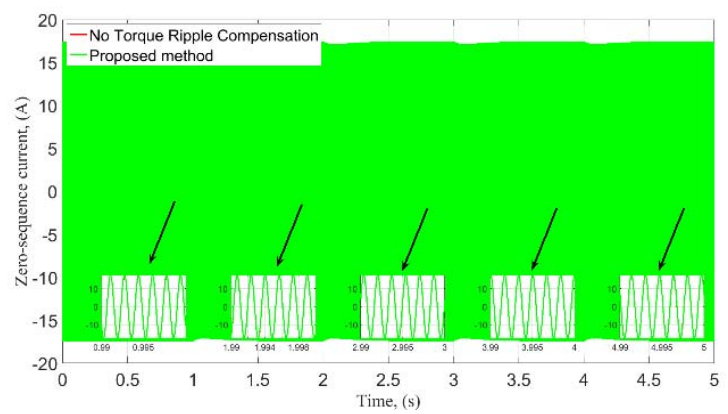

Fig. 11 - Zero-sequence current $\left(i_{0}\right)$ comparison

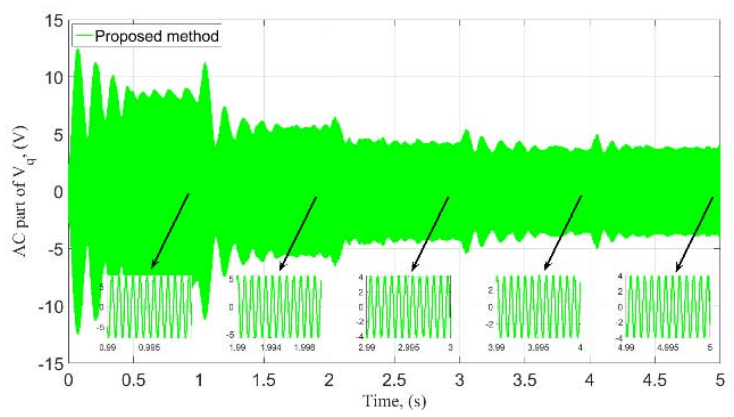

Fig. 12 - AC part of the quadrature axis voltage $\left(V_{q A C}\right)$

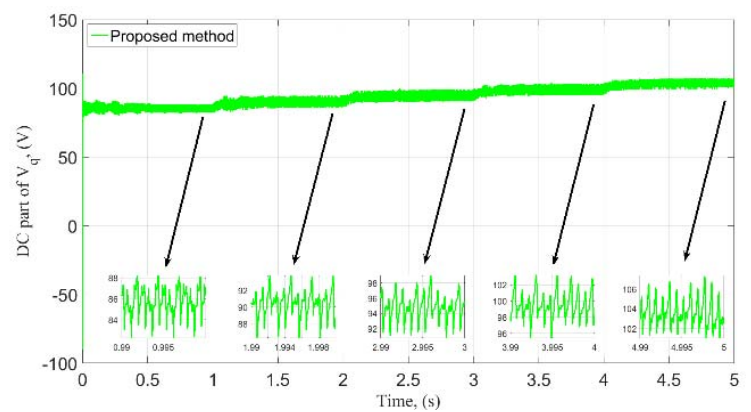

Fig. 13 - DC part of the quadrature axis voltage $\left(V_{q D C}\right)$

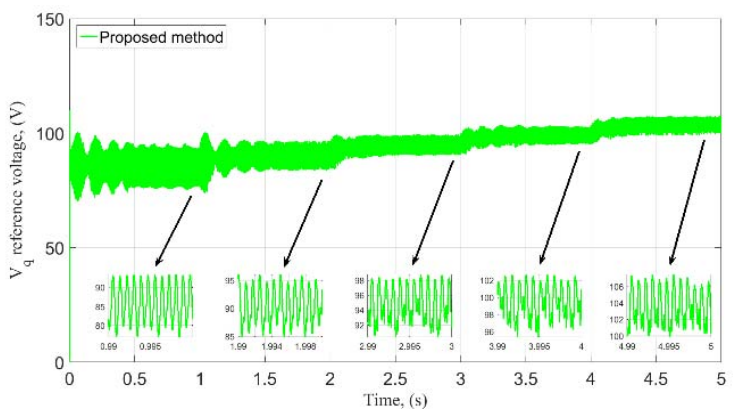

Fig. 14 - Quadrature axis voltage $\left(V_{q}\right)$

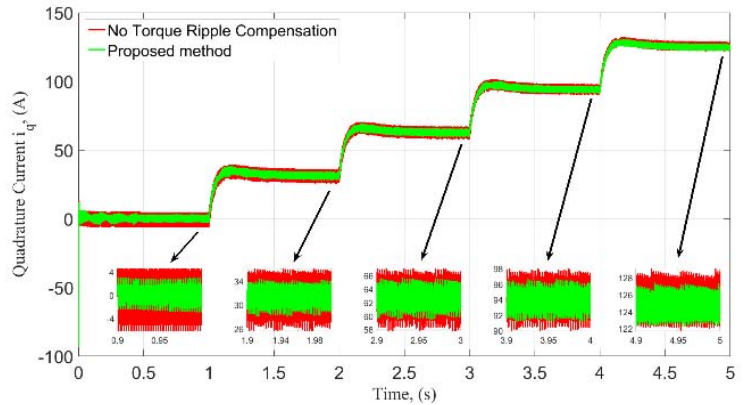

Fig. 15 - Quadrature axis current $\left(i_{q}\right)$ comparison

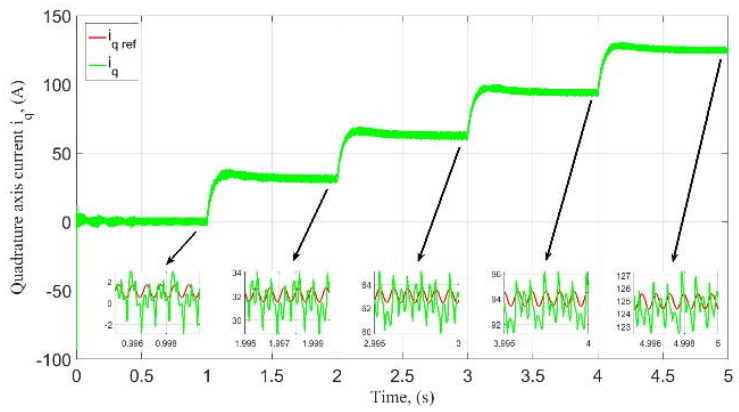

Fig. 16-Quadrature axis current with reference (proposed control method)

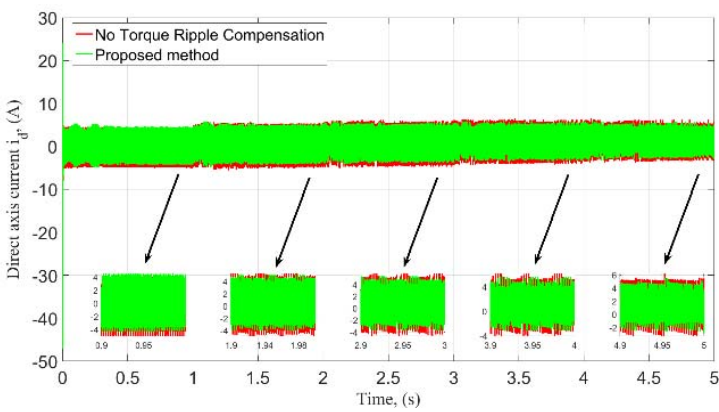

Fig. 17 - Direct axis current $\left(i_{d}\right)$ comparison

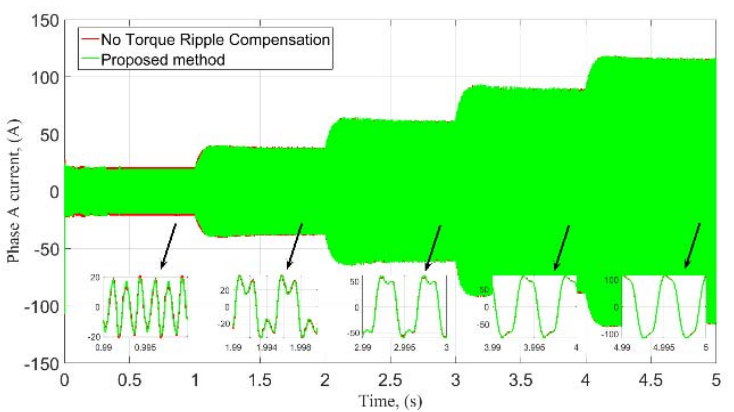

Fig. 18 - Phase A current $\left(i_{a}\right)$ comparison

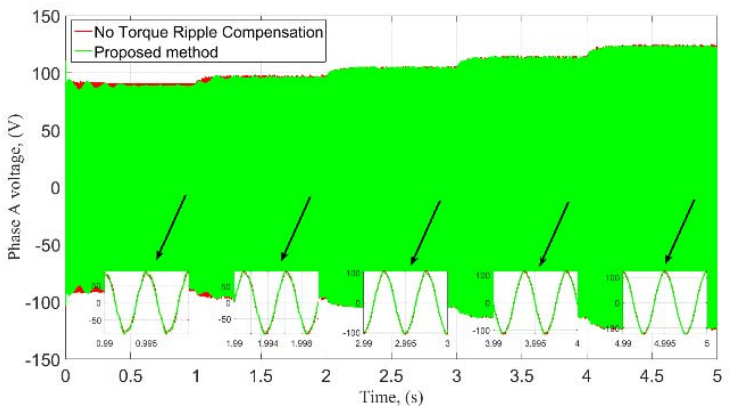

Fig. 19 - Phase A voltage $\left(V_{a}\right)$ comparison 


$$
\left|i_{0}\right|=\sqrt{\left(i_{0}{ }^{\prime}\right)^{2}+\left(q i_{0}{ }^{\prime}\right)^{2}}
$$

The same SOGI based PLL block is used to identify the amplitude of the output of the resonant controller in order to be used in the voltage limiter to limit $V_{q D C}$ reference value, according to the equation (25) derived from voltage limit equation (24).

$$
\begin{gathered}
V_{D C}=\sqrt{\left(V_{q D C_{-} l i m}+\left|V_{q A C}{ }^{*}\right|\right)^{2}+V_{d}^{2}} \\
V_{q D C_{-} l i m}=\sqrt{V_{D C}{ }^{2}-V_{d}^{2}}-\left|V_{q A C}{ }^{*}\right|
\end{gathered}
$$

where, $V_{D C}$ is the bus voltage, $V_{q D C \_l i m}$ is the limit value of the output of quadrature current loop PI, $\left|V_{q A C}{ }^{*}\right|$ is the amplitude of the output oscillating signal of RC, and $V_{d}$ is the quadrature voltage.

During the simulation, the speed value was kept the same, at $200 \mathrm{~Hz}$ electrical frequency. The torque was increased in the following steps: $1,10,20,30$, and $40 \mathrm{Nm}$ every second, respectively. The simulation results are shown in Fig. 10 - Fig. 19. It is clear that when the disturbance due to the inverter switching is introduced, the picture changes dramatically. The electrical torque ripple becomes considerably higher than the previously calculated value. Fig. 10 provides a comparative visual depiction of the electromagnetic torque output of the system shown in Fig. 5.

The proposed method is struggling to fully suppress the torque ripple, however, as it can be seen from the more accurate simulation results shown in Fig. 10 that there is still an improvement in the overall torque quality. The values of the absolute torque ripple were measured at each load torque step and recorder in TABLE II.

TABLE II TORQUE QUALITY IMPROVEMENT

\begin{tabular}{|c|c|c|c|}
\hline \multirow{2}{*}{$\begin{array}{c}\text { Load } \\
\text { torque, } \\
\text { (Nm) }\end{array}$} & \multicolumn{2}{|c|}{$\begin{array}{c}\text { Peak-to-Peak Torque } \\
\text { Ripple, (Nm) }\end{array}$} & \multirow{2}{*}{$\begin{array}{c}\text { Improvement due } \\
\text { to the proposed } \\
\text { method, (\%) }\end{array}$} \\
\cline { 2 - 3 } & $\begin{array}{c}\text { No } \\
\text { compensation }\end{array}$ & $\begin{array}{c}\text { Proposed } \\
\text { method }\end{array}$ & \\
\hline 1 & 3.29 & 1.66 & 49.50 \\
\hline 10 & 3.05 & 1.72 & 43.53 \\
\hline 20 & 2.71 & 1.65 & 39.20 \\
\hline 30 & 2.31 & 1.44 & 37.86 \\
\hline 40 & 2.28 & 1.44 & 37.04 \\
\hline
\end{tabular}

Considering the results shown in TABLE II the proposed method still results in the improvement of the torque quality of up to $49.5 \%$.

The current ripple of both the quadrature and the direct axis currents shown in Fig. 15 and Fig. 17 appears to be reduced as well. However, according to Fig. 16, it appears that the quadrature current is not following the reference, however, judging by the stability of the generated AC part of the quadrature axis voltage in Fig. 12 it can be concluded that the torque ripple harmonic due to the third harmonic back EMF that was subjected to be suppressed was, indeed, suppressed.

\section{CONCLUSION}

The third harmonic of the back EMF causes the zero sequence currents to circulate in the OEW PMSM drives with common DC bus. This results in the degradation of the torque quality of such a system. The existing methods aimed at improving the torque quality cannot be used when a system with the low leakage inductance is introduced as under such condition it is hard to maintain the control of the zero sequence component. This paper proposed a control method that employs a proportional integral plus adaptive resonant controller for regulation of the quadrature current in order to compensate the torque ripple caused by the zero sequence components.

The basic simulation of the proposed control showed a complete elimination of the torque ripple due to the zero sequence component of the OEW PMSM without the need of introducing the zero sequence voltage component. However, a more detailed simulation showed that due to the inverter switching the current noise substantially increased. Nevertheless, it was confirmed by the means of simulation that the proposed method of improving the output torque quality of such machines results in an improvement of the overall torque quality even when the current noise due to the inverter switching was introduced.

\section{REFERENCES}

[1] P. Zanchetta, C. Gerada, A. Lidozzi, M. Degano, F. Crescimbini and L. Solero, "Performance evaluation of converter topologies for high speed Starter/Generator in aircraft applications," in 40th Annual Conference of the IEEE Industrial Electronics Society, Dallas, TX, 2014.

[2] H. Zhan, Z. Q. Zhu, M. Odavic and Y. Li, “A Novel Zero-Sequence Model-Based Sensorless Method for Open-Winding PMSM With Common DC Bus," IEEE Transactions on Industrial Electronics, vol. 63, no. 11,pp. 6777 - 6789, 2016.

[3] L. Rovere, A. Formentini, G. L. Calzo, P. Zanchetta and T. Cox, "IGBT-SiC dual fed open end winding PMSM drive," in Electric Machines and Drives Conference (IEMDC), 2017 IEEE International, Miami, 2017.

[4] Q. An, J. Liu, Z. Peng, L. Sun and L. Sun, "Dual-Space Vector Control of Open-End Winding Permanent Magnet Synchronous Motor Drive Fed by Dual Inverter," IEEE Transactions on Power Electronics, vol. 31, no. 12, pp. 8329-8342, 2016.

[5] N. Kalantari and L. A. C. Lopes, "Reduction of Dead-Time Effect on the Common Mode Voltage of an Open-End Winding Machine," in 2016 IEEE 25th International Symposium on Industrial Electronics (ISIE), Santa Clara, CA, USA, 2016.

[6] A. Somani, R. K. Gupta, K. K. Mohapatra and N. Mohan, "On the Causes of Circulating Currents in PWM Drives With Open-End Winding AC Machines," IEEE Transactions on Industrial Electronics, vol. 60, no. 9, pp. 3670-3678, 2013.

[7] H. Zhan, Z. Q. Zhu and M. Odavic, "Nonparametric Sensorless Drive Method for Open-Winding PMSM Based on Zero-Sequence Back EMF With Circulating Current Suppression," IEEE Transactions on Power Electronics, vol. 32, no. 5, pp. 3808 - 3817, 2017.

[8] J. Korhonen, J. Honkanen, T. J. Kärkkäinen, J. Nerg and P. Silventoinen, "Modulation and control methods to reduce zero sequence current in open-end winding motors," in Electric Machines and Drives Conference (IEMDC), 2017 IEEE International, Miami, FL, USA, 2017.

[9] N. M. Said, M. Priestley, R. Dutta and J. E. Fletcher, "Torque ripple minimization in dual inverter open-end winding PMSM drives with non-sinusoidal back-EMFs by harmonic current suppression," in IECON 2016, Florence, 2016.

[10] Y. Zhou and H. Nian, "Zero-Sequence Current Suppression Strategy of Open-Winding PMSG System With Common DC Bus Based on Zero Vector Redistribution," IEEE Transactions on Industrial Electronics, vol. 62, no. 6, pp. 3399 - 3408, 015. 
[11] P. Krause, O. Wasynczuk, S. Sudhoff and S. Pekarek, Analysis of Electric Machinery and Drive Systems, Hoboken: John Wiley \& Sons Inc, 2013.

[12] A. Lidozzi, G. L. Calzo, L. Solero and F. Crescimbini, "Multiple resonant controller with load-adaptive phase compensation capabilities," in IECON 2013 - 39th Annual Conference of the IEEE Industrial Electronics Society, Vienna, Austria, 2013.
[13] M. Ciobotaru, R. Teodorescu and F. Blaabjerg, "A new singlephase PLL structure based on second order generalized integrator," in 2006 37th IEEE Power Electronics Specialists Conference, Jeju, 2006 